\title{
Addressing the Impact of Industrialized Components on the Cost of Temporary Heating in Cold-climate Regions
}

\author{
Regina DIAS FERREIRA ${ }^{1 *}$, Beda BARKOKEBAS ${ }^{1}$, Lana SECCHI ${ }^{2}$, Mustafa GÜL ${ }^{3}$, YuXiang \\ $\mathrm{CHEN}^{4}$ and Mohamed AL-HUSSEIN ${ }^{5}$ \\ ${ }^{1}$ PhD student, Department of Civil \& Environmental Engineering, University of Alberta \\ ${ }^{2}$ MSc student, Department of Civil \& Environmental Engineering, University of Alberta \\ ${ }^{3}$ Assistant Professor, Department of Civil \& Environmental Engineering, University of Alberta \\ ${ }^{4}$ Assistant Professor, Department of Civil \& Environmental Engineering, University of Alberta \\ ${ }^{5}$ Professor, Department of Civil \& Environmental Engineering, University of Alberta \\ ${ }^{*}$ Corresponding author's e-mail: rdferreira@ualberta.ca
}

\begin{abstract}
In countries with cold climates such as Canada, the cost of providing space heating during the construction phase, also known as temporary heating, results in a significant additional construction cost, which causes budget deviations thus affecting the project's financial performance. In fact, the estimation of temporary heating is commonly overlooked due to the uncertainties such as weather forecast and the project's actual onsite schedule. The cost of temporary heating comprises two parts: (1) the cost of equipment rental, and (2) the fuel consumption required to heat a given area when the temperature falls below a certain threshold. The fuel consumption of the equipment is related to the temperature and exposure of the building's envelope to the current weather conditions. Thus, the construction of the building envelope is critical to the reduction of fuel consumption and the consequent temporary heating cost of the project. In this context, the research presented in this paper aims to estimate the impacts of temporary heating for various constructive methods, such as the traditional stick-built practice and a few variations of panelized construction (in regard to the insulation used), by developing a simulation model to observe the variation of weather data, construction schedule, and fuel consumption for each scenario. To perform this analysis, a 4-story residential building located in the city of Edmonton, Alberta, Canada, is used as a case study in which the proposed scenarios are compared in order to address the advantages of industrialized components in reducing the cost of temporary heating.
\end{abstract}

\section{KEYWORDS}

Temporary heating; Offsite construction; Pre-fabricated walls; Cold-climate

\section{INTRODUCTION}

Offsite construction is widely utilized in North America, due to its effectiveness for building structures in a controlled and fast-paced environment (Mohsen et al., 2008; Olearczyk et al., 2014). 
The idea of separating activities from the traditional process and allowing building components to be manufactured and installed onsite presents a significant paradigm shift in the current stick-built practice. Despite its added value, the advantages of offsite construction (or pre-fabrication) remain to be substantiated across the industry (Smith and Quale, 2016).

In fact, the pre-fabrication of building components still carries a stigma of incurring a high initial project cost (Elnaas et al., 2014; Rahimian et al., 2017), which imposes a challenge in its adoption, especially in strategic sectors of construction such as housing. According to Zhai et al. (2014), most stakeholders compare pre-fabrication and stick-built methods in a short-term timeframe, thus undervaluing the advantages of shorter schedules to the cost of the whole project. Therefore, evaluating the whole financial impact induced from pre-fabrication is key for its application on a larger scale. In countries with cold-climate conditions, the cost of temporary heating for a project is often neglected until problems arise in the field, which commonly causes friction between owners and general contractors (Schlick, 1983).

Temporary heating during construction imposes a significant cost for the overall project while being difficult to estimate due to its interdependency on the weather forecast and onsite schedule performance. Quale et al. (2012) attribute an uncertainty of $\pm 50 \%$ while estimating the required amount of onsite temporary heating, while Li et al. (2017) address the quantification of onsite heating as one of the key aspects to demonstrate the superior performance of pre-fabrication methods over the traditional stick-built practice. The cost of temporary heating is divided into two parts: (a) equipment rental and (b) fuel consumption. Furthermore, the fuel consumption is related to two factors: (a) weather conditions and (b) building envelope thermal resistance (RSI).

In light of the information provided, the aim of the research presented in this paper is to compare the impacts of conventional (stick-built) and pre-fabrication methods on the cost of temporary heating. In order to do so, a discrete event simulation (DES) model is developed to calculate the time and temporary heating required to build the structure and envelope of a 4-story residential building.

\section{METHODS}

The methods followed to conduct the present study are presented in this section. As indicated in Figure 1, the inputs used in this research methodology include location of the project; weather information such as historical daily temperature; information on building envelope design; properties of construction materials (i.e., thermal resistance, thickness, and thermal conductivity); construction schedule; cost of temporary heating; and other relevant project information (e.g., building geometry such as exterior walls and roof dimensions). Based on the experience of specialists and current practice, the present research considers the following criteria: (a) once the indoor temperature of the building is below $10^{\circ} \mathrm{C}$, the heating equipment is activated; (b) if temporary heating is required, it will be provided for an entire day (i.e., 24 hours); (c) construction activities occur only during week days, but the equipment will remain active during weekends if needed; (d) the analyses are performed using days as the unit of time; (e) the indoor building temperature is calculated using steady state heat conduction principles; and (f) the heating equipment will start being used after the entire building structure is framed. Once the inputs and criteria are defined, several steps are followed in order to achieve the objective of this study. 

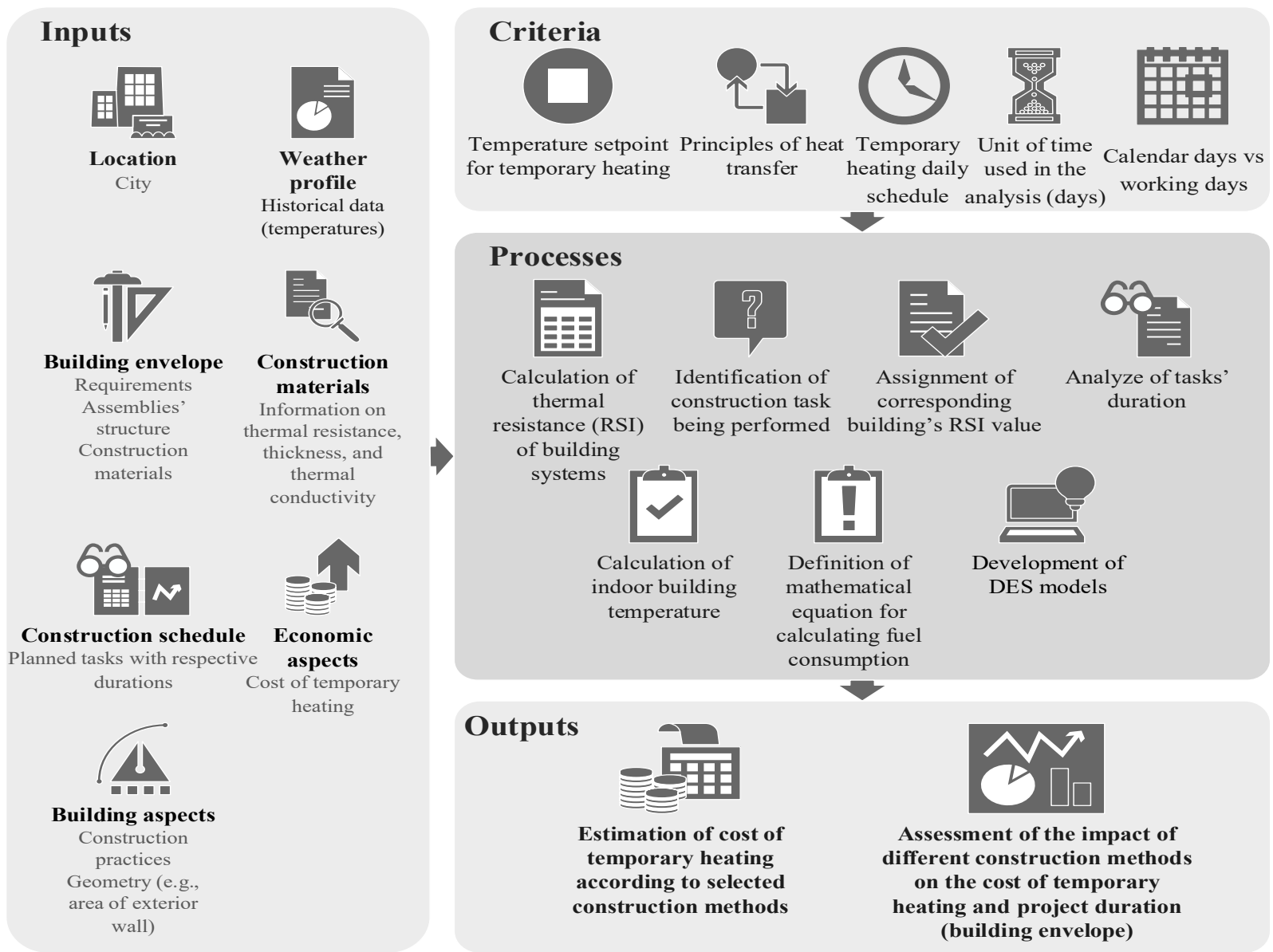

Figure 1. Overview of research methodology.

Building envelope thermal resistance. The effective RSI value of relevant building envelope systems is calculated, accounting for the properties of construction materials used in each assembly. In addition to these calculated effective RSI values, which represent the RSI value achieved once the construction of a building envelope system is complete, intermediate effective RSI values are also estimated based on project schedule. Properties of construction materials related to the first step of this research methodology are acquired from the 2017 ASHRAE Handbook-Fundamentals (ASHRAE, 2017) and the Alberta Building Code 2014 (NRCan, 2014). It is important to note that the building envelope's thermal resistance increases as the building envelope is built (e.g., insulation of exterior walls, roofing, etc.), thus affecting the interior temperature of the building as well as the heating requirements for the project at a certain time.

Simulation of construction tasks. The assignment, sequence, and duration of each task is provided in order to develop the DES model using Simphony.NET software. This model aims to calculate the total duration and fuel required to heat the building during its construction. When assigning the duration of each task, the development of distributions is encouraged over a deterministic value (i.e., a triangular distribution of $(8,12,10)$ over a fixed duration of 10 days) in order to reflect the uncertainty of onsite operations. For the scope of this research, only tasks related to the construction of the structure and envelope of the building are considered. 
Project progress and building's thermal resistance. The project schedule is verified to identify the task of which the project is carrying out on a specific calendar day $(n)$. This information is important in order to determine which intermediate effective RSI value is applicable and, hence, the total effective RSI value of the entire building at day $n$.

Calculating interior temperature. Once the information regarding the construction progress and the effective RSI value of the building at day $n$ is determined, the interior temperature of the building at day $n$, referred to herein as $\mathrm{T}_{\text {int. (n), }}$, is calculated. To determine $\mathrm{T}_{\text {int. }}(\mathrm{n})$, Equation (1), which is based on the steady state heat conduction principle (Karwa, 2017), is applied. As observed in Equation (1), solar heat gain is not accounted for in the present study and the outdoor temperature, referred to as $T_{\text {out. (n) }}$, is required to estimate $T_{\text {int. }}(n)$. $T_{\text {out. }}(n)$ is obtained from a distribution based on historical temperatures measured in the city of Edmonton from the years 1993 to 2012 (University of Alberta, 2018).

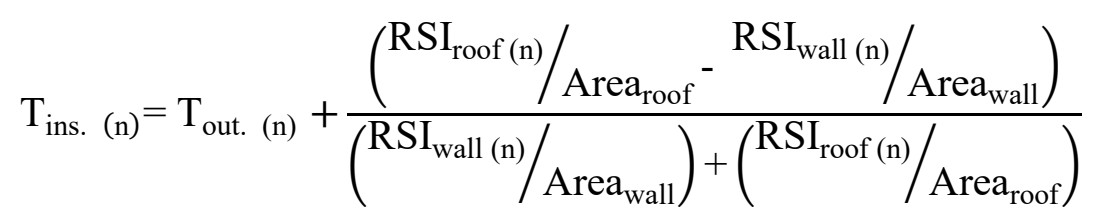

Heating requirement and consumption. The need for temporary heating at day $n$ is verified. If the calculated $\mathrm{T}_{\text {int. (n) }}$ is below $10^{\circ} \mathrm{C}$, temporary heating is required, and thus, its cost is estimated; otherwise, no action is pursued. To estimate the additional cost due to the need for temporary heating, the cost of renting the heating equipment is added to the cost of fuel consumption of the heating equipment. The latter is calculated using Equation (2), which is derived based on information provided by regional suppliers, while the former is a constant value, which can also be estimated by performing a market survey.

$$
\text { Consumption }_{(\mathrm{n})}=\text { Quantity of heaters required } \times \frac{24 \text { hours }}{\text { day }} \times\left(-0.13 \times \mathrm{T}_{\text {ins. }}(\mathrm{n})+12.00\right)
$$

In light of the information provided above, it is noted that given a specific calendar day $(n)$, the following factors are determined (in order of appearance): project progress, effective RSI value of the entire building, outdoor temperature, and indoor building temperature.

\section{CASE STUDY}

The methodology described in the Methods Section of this paper is applied to a 4-story residential building located in the city of Edmonton, Alberta, Canada. The chosen building has an L-shaped floor plan, consists of 64 apartment units, and has a construction area of $6,538 \mathrm{~m}^{2}$ in wood-frame structure and concrete underground parkade.

In the present study, the construction of the selected building is simulated considering three construction methods: stick-built (SB), pre-fabricated 1 (P1), and pre-fabricated 2 (P2). SB refers to the current stick-built practice in which the framing task, as per Figure 2, consists of assembling wall panels on site and finishing the exterior with oriented strand board (OSB). P1 addresses the scenario in which the same task includes the exterior finishes and windows (building wrap, siding, 
and windows tasks), while P2 includes - in addition to the tasks in P1-insulation (including vapour barrier) and drywall boarding tasks, thus installing pre-fabricated closed panels on site.

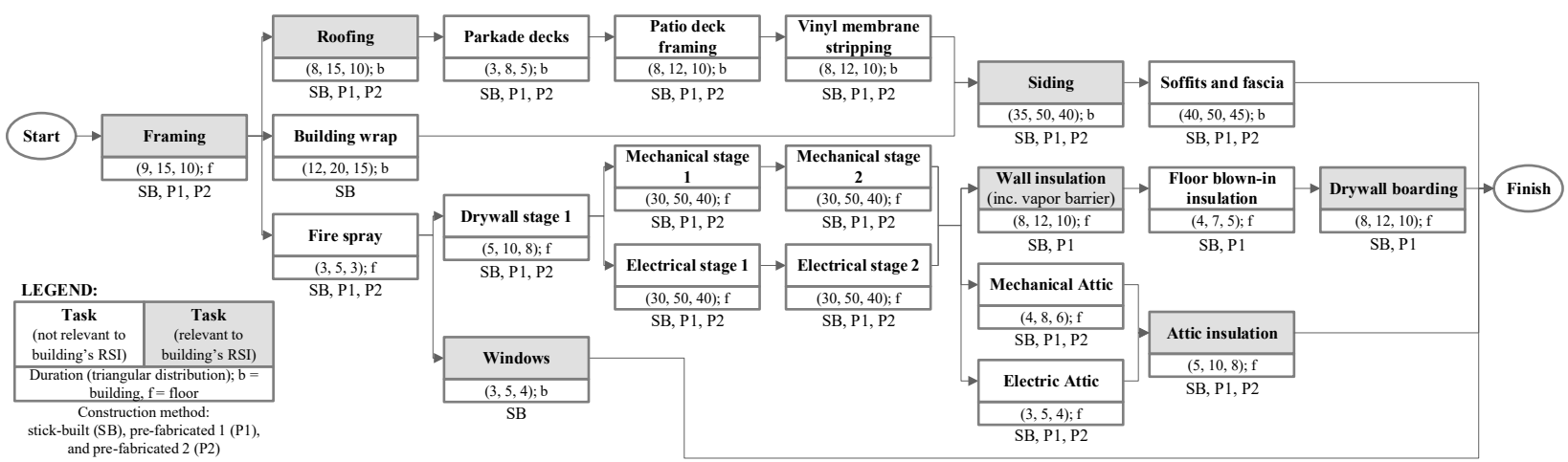

Figure 2. Summary of construction methods assessed in the present study and their similarities and dissimilarities.

Figure 2 and Figure 3, respectively, provide a visual representation of the analyzed construction methods as well as their similarities/dissimilarities, which are related to total project duration (i.e., sequence of tasks), and effective RSI values. Since the RSI values of the building are determined based on material properties, alterations of construction tasks result in different RSI values, as detailed in Figure 2-e.g., after "Task 1W", the RSI value of the building is 0.04 in SB, 0.30 in P1, and 1.66 in $\mathrm{P} 2$.

\begin{tabular}{l} 
P1 \\
\cline { 3 - 5 }
\end{tabular}

Figure 3. Overview of relevant information and RSI value of case study building.

In the context of the presented case study, it is assumed that five propane-fired indirect heating units are demanded on site to provide the heating required to maintain $\mathrm{T}_{\text {ins. }}(\mathrm{n}) \geq 10^{\circ} \mathrm{C}$, based on consultation with a local temporary heating equipment supplier and project managers on site. Figure 4 depicts the cost breakdown of the temporary heating equipment, accessories, and amount 
of propane required for the case study building per week, as well as the delivery fee and cost per litre, respectively. The start date of all scenarios is 30 April and each are simulated 1,000 times. The average fuel consumption of these heaters is then estimated per day by applying Equation (2). The results obtained through the developed simulation models are presented in the following section (Results and Discussion).

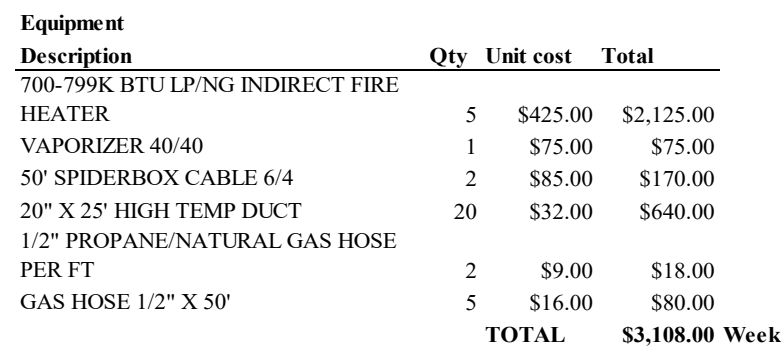

\begin{tabular}{lcrc}
$\begin{array}{l}\text { Delivery } \\
\text { Description }\end{array}$ & Qty & Unit cost & Total \\
\hline TRANSPORTATION & 1 & $\$ 17.00$ & $\$ 17.00$ \\
SURCHARGE & 1 & $\$ 91.00$ & $\$ 91.00$ \\
ENVIRONMENTAL & 1 & $\$ 85.00$ & $\$ 85.00$ \\
DELIVERY CHARGE & 1 & $\$ 85.00$ & $\$ 85.00$ \\
PICKUP CHARGE & \multicolumn{4}{c}{ TOTAL } & $\$ \mathbf{\$ 2 7 8 . 0 0}$ Fee \\
& & Unit cost & Total \\
Material & Qty & \multicolumn{3}{c}{$\$ 0.59$} & $\$ 0.59$ \\
PROPANE & \multicolumn{4}{c}{ TOTAL } & $\$ \mathbf{0 . 5 9}$ Litre
\end{tabular}

Figure 4. Cost breakdown for propane-fired temporary heating.

\section{RESULTS AND DISCUSSION}

The results obtained in this research present information related to project duration, temporary heating cost, and its consumption. Figure 5 demonstrates the average duration and cumulative heating cost based on three scenarios. To be concise, the results are demonstrated beginning from week 16 , the time at which the heating becomes necessary $\left(\mathrm{T}_{\text {int. }}(\mathrm{n})<10\right)$ and the building is framed in scenario $\mathrm{P} 2$.

Figure 5 also demonstrates significant reductions in both duration (13\% and $33 \%$ for P1 and P2, respectively) and heating cost (17\% and $48 \%$ for $\mathrm{P} 1$ and $\mathrm{P} 2$, respectively) when comparing the prefabricated scenarios with the current stick-built (SB) practice. The duration reduction is anticipated due to the reduction in the total duration and compression of tasks previously mentioned in Figure 2. The reduction in heating cost is related to shorter durations (reduced equipment cost), and reduced propane consumption, which are affected by the outdoor temperature, indoor temperature, and the speed at which the building envelope is built.

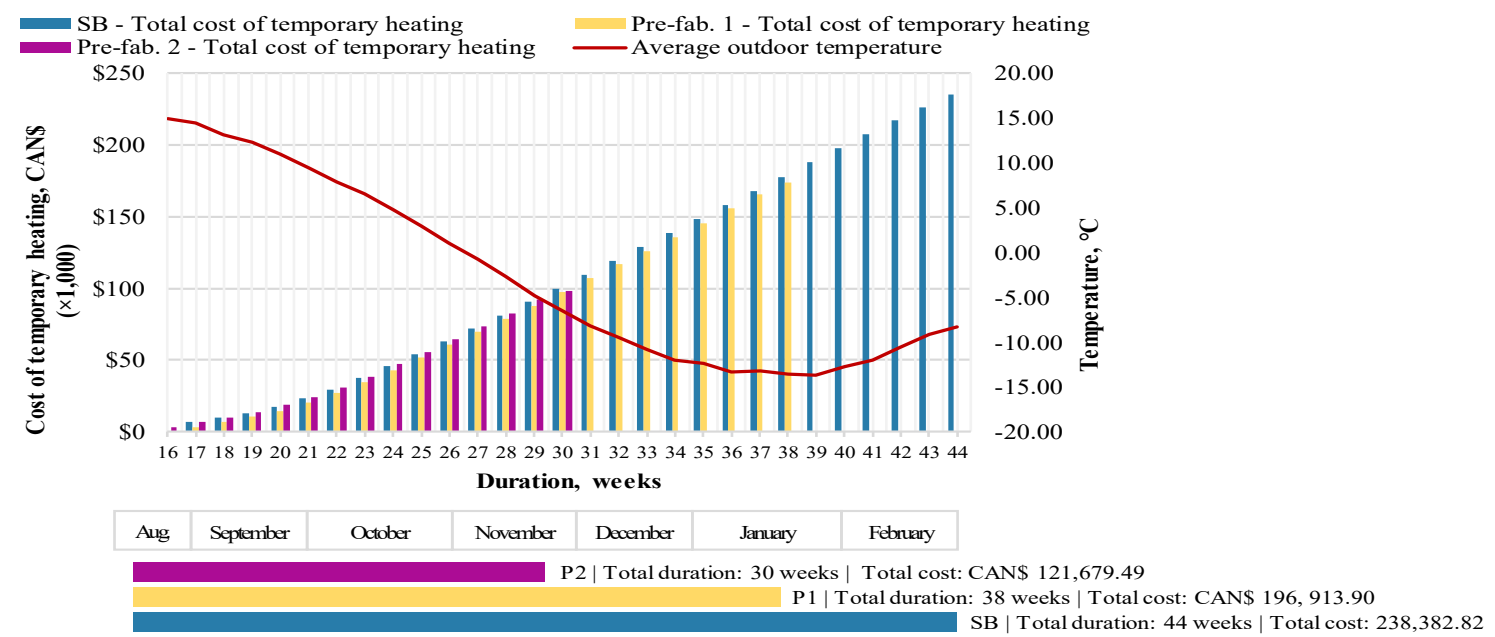

Figure 5. Cost and duration of simulated scenarios. 
Figure 6 depicts the weekly propane consumption, as well as the average indoor and outdoor temperatures for scenarios SB and P1 in order to investigate the influence of the construction speed on the thermal resistance of the building. Scenario P2 is not presented in this figure given that its thermal resistance varies little over the project duration (wall panels are installed with final thermal resistance as discussed in the Case Study Section). As Figure 6 indicates, the difference between indoor and outdoor temperatures are not significantly affected during the project duration, concluding that the thermal resistance of the building is not representative in the propane consumption for temporary heating. The outdoor temperature imposes a greater influence in propane consumption (lower temperatures leads to greater use) and is dependent upon the location and start date of the project.
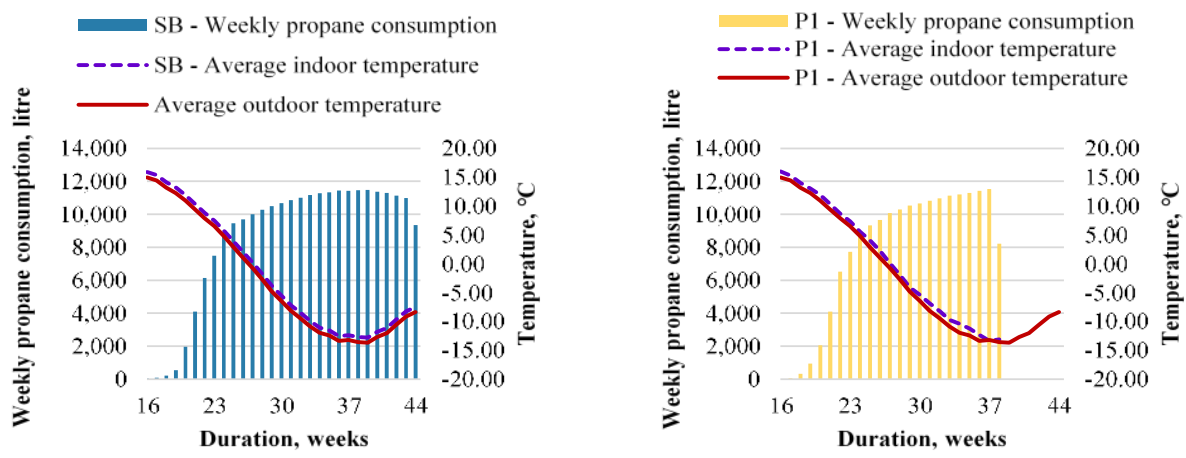

Figure 6. Weekly propane consumption and average indoor and outdoor temperatures for scenarios $\mathrm{SB}$ and $\mathrm{P} 1$.

Upon the analysis of the results demonstrated in Figure 5 and Figure 6, it can be concluded that the temporary heating cost is driven by the duration of the project (i.e., number of weeks for which the equipment is rented), and outdoor temperature (amount of propane consumed), which is a combination of the start date and location of the project.

\section{CONCLUSION}

This research intends to provide a deeper understanding of the financial impacts incurred from the use of pre-fabricated wall panels in the residential sector. Through the simulation of three different scenarios - one reflecting the current stick-built practice and two reflecting different pre-fabricated options - this research identifies significant savings ( $17 \%$ and $48 \%$ for P1 and P2, respectively) in temporary heating during the construction phase.

The savings in heating are a product of several variables (e.g., schedule performance, weather conditions, thermal resistance of the building, etc.), but are more directly related to the project duration (reduced equipment rental), outdoor temperature (which drives the propane consumption and is influenced by the start date), as well as the project location, which influences the cost of heating solutions and outdoor temperatures.

The authors intend to explore as future research the temporary heating cost savings incurred from pre-fabrication in other climate regions, other periods of the year (i.e., different start dates), and 
other heating sources (e.g., natural gas, electric, diesel, etc.). Regarding the limitations of this research, it is important to state that solar heat gain is not accounted for in the determination of indoor temperature of a building, which will also be included in future research opportunities.

\section{ACKNOWLEDGEMENTS}

The authors would like to acknowledge Michael Kopp from Landmark Group of Companies for the support received. The authors would also like to extend their gratitude to Juan Manrique, Jonathan Stollery, and Corey Nicholson for their valuable information provided during the development of this research.

\section{REFERENCES AND CITATIONS}

ASHRAE. (2017). 2017 ASHRAE handbook: fundamentals. Atlanta, GA : ASHRAE, 2013]; SI edition.

Elnaas, H., Gidado, K., and Philip, A. P. (2014). "Factors and drivers effecting the decision of using off-site manufacturing (OSM) systems in house building industry." Journal of Engineering, Project, and Production Management, Association of Engineering, Project, \& Production Management, 4(1), 51.

Karwa, R. (2017). "One-Dimensional Steady State Heat Conduction." Heat and Mass Transfer, Springer Singapore, Singapore.

Li, H. X., Zhang, L., Mah, D., and Yu, H. (2017). "An integrated simulation and optimization approach for reducing $\mathrm{CO} 2$ emissions from on-site construction process in cold regions." Energy and Buildings, 138, 666-675.

Mohsen, O. M., Knytl, P. J., Abdulaal, B., Olearczyk, J., and Al-Hussein, M. (2008). "Simulation of modular building construction." Simulation Conference, 2008. WSC 2008. Winter, 24712478 .

NRC, of Canada, N. R. C., and Alberta. (2014). Alberta Building Code 2014. National Research Council of Canada, Ottawa.

Olearczyk, J., Al-Hussein, M., and Bouferguène, A. (2014). "Evolution of the crane selection and on-site utilization process for modular construction multilifts." Automation in Construction, Elsevier B.V., 43, 59-72.

Quale, J., Eckelman, M. J., Williams, K. W., Sloditskie, G., and Zimmerman, J. B. (2012). "Construction Matters: Comparing Environmental Impacts of Building Modular and Conventional Homes in the United States." Journal of Industrial Ecology, 16(2), 243-253.

Rahimian, F. P., Goulding, J., Akintoye, A., and Kolo, S. (2017). "Review of Motivations, Success Factors, and Barriers to the Adoption of Offsite Manufacturing in Nigeria." Procedia Engineering, 196, 512-519.

Schlick, H. (1983). "Temporary heating in construction contracts." Journal of Construction Engineering and Management, A. J. Etkin Construction Co., 109(4), 447-459.

Smith, R. E., and Quale, J. D. (2016). Offsite Architecture: Constructing the Future. Routledge, New York.

University of Alberta. (2018). "Simphony.NET 4.6 Homepage."

Zhai, X., Reed, R., and Mills, A. (2014). "Factors impeding the offsite production of housing construction in China: an investigation of current practice." Construction Management and Economics, 32(1-2), 40-52. 